\title{
Compreensão de sentenças em crianças com desenvolvimento normal de linguagem e com distúrbio específico de linguagem
}

\author{
Marina Leite Puglisi ${ }^{1}$
}

Puglisi ML. Compreensão de sentenças em crianças com desenvolvimento normal de linguagem e com distúrbio específico de linguagem [tese]. São Paulo: Faculdade de Medicina da Universidade de São Paulo; 2010.

Introdução: Tarefas de compreensão de sentenças exigem grandes demandas de processamento linguístico e consistem em uma ferramenta útil para investigar diferenças entre o desempenho de crianças de diferentes grupos. O objetivo desta tese foi verificar a existência dos efeitos crosslinguísticos, sócio-econômicos e do Distúrbio Específico de Linguagem (DEL) nas habilidades de compreensão de sentenças de crianças pequenas. Método: Participaram deste estudo 269 crianças de 4 a 6 anos, divididas em quatro grupos: 1) Brasileiras de escola pública; 2) Brasileiras de escola privada; 3) Inglesas de escola pública; e 4) Brasileiras com DEL, de escola pública. As sentenças utilizadas neste estudo exigiam a compreensão de duas variáveis lingüísticas: a ordem das palavras e o morfema gramatical de número. Resultados: O efeito sócioeconômico foi caracterizado por uma dificuldade específica em processar a informação morfológica de número. Houve um pequeno efeito crosslinguístico, especialmente relacionado à compreensão da ordem das palavras. A principal diferença entre os grupos foi encontrada para as crianças com DEL: enquanto as mais novas apresentaram padrões atípicos de resposta, as mais velhas tiveram um desempenho semelhante ao das crianças mais novas, em desenvolvimento normal de linguagem, pertencentes a baixos níveis sócio-econômicos. Conclusões: Os achados indicaram que o desempenho de crianças de 4 a 6 anos nesta prova de compreensão foi diferente de acordo com o grupo estudado, evidenciando efeitos sócio-econômicos, crosslinguísticos (embora em menor extensão) e do DEL. Esta prova foi particularmente útil para discriminar as crianças com DEL das demais, contribuindo para o diagnóstico da patologia.

Tese apresentada à Faculdade de Medicina da Universidade de São Paulo para obtenção do título de Doutor em Ciências, sob orientação da Profa. Dra. Debora Maria Befi-Lopes.

(1) Doutora, Pesquisadora colaboradora do Laboratório de Investigação Fonoaudiológica em Desenvolvimento da Linguagem e suas Alterações do Departamento de Fisioterapia, Fonoaudiologia e Terapia Ocupacional da Faculdade de Medicina da Universidade de São Paulo - USP - São Paulo (SP), Brasil. Endereço para correspondência: Marina Leite Puglisi. R. João Alexandre Rochadel, 76, Brooklin, São Paulo (SP), Brasil, CEP: 04565-010. E-mail: marinapuglisi@uol.com.br 